\title{
A BORDERLINE CASE OF NEUROTIC EXCORIATIONS *
}

\author{
WILliAM ALLEN PUSEY, M.D. \\ CHICAGO
}

MacKee and Senear and I have recently called attention to a group of self-inflicted eruptions, under the title "Neurotic Excoriations." In their slight degrees they are familiar, but the more extreme forms of the condition, while their character is doubtless recognized, have not hitherto been reported in this country. The subject has been described carefully by English authors, notably by Erasmus Wilson, Tilbury Fox, and Adamson. I believe the cases are so frequent that the subject should be impressed on our minds.

The clinical pictures differ from the ordinary feigned eruptions, and the conditions differ essentially from feigned eruptions in the mental states of the patients. In a feigned eruption the patient is secretive and tries to cover up the fact that the eruption is selfproduced. In neurotic excoriations the patient has a strong impulse to produce damage to the skin and, while he may not suggest the part that he plays in his injuries, he makes no attempt to conceal it when inquiry is made. His is an entirely different mental attitude from that of the malingerer.

I have recently seen a case in which the amount of destruction of the skin equaled that in many cases of typical malingering, but in this case the psychic condition was that seen in neurotic excoriations. It may perhaps be regarded as a borderline case between the two conditions.

REPORT OF A CASE

History.-Miss X., aged 26 , a nurse, who acted as an attendant in a doctor's office, presented herself in December, 1919, with a chronic ulcer of the back of the left hand. There was an atrophic, ulcerating scar extending the full width of the hand, and from the wrist to within a finger's breadth of the knuckles. In the scarred area there were numerous round, crescentic, irregular superficial ulcers. These superficial ulcers were covered with red granulations in which there were numerous islets of growing epithelium. There were other small deeper ulcers, some being in the skin outside the scar, and the whole area was more or less covered with yellowish pus crusts (see figure).

In September, 1918, she burned the left hand with concentrated lye. The burn healed with the formation of a thin scar. The scar was fissured from time to time across the wrist, but the fissures readily healed with zinc oxid ointment. About five weeks before presentation a fissure appeared, but this

* Read at the Forty-Third Annual Meeting of the American Dermatological Association, Asheville, N. C., April 22-24, 1920. 
did not heal on the application of the zinc oxid ointment; the scar began to ulcerate, and the ulceration spread rapidly. Dressings of zinc oxid ointment and other bland ointments, of balsam of Peru, wet dressings of salt solution, hydrogen peroxid solution and the surgical solution of chlorinated soda (Dakin's solution) had been used without avail; the ulcerations continued to spread.

There was nothing significant in the patient's history. Her general health had been good. She slept well. She was an intelligent woman, and her physician employer thought that she was not nervous or high strung, although seven years before, at a time of family difficulties, she showed some tendency to hysteria. Her pharynx and conjunctivae were anesthetic.

The configuration on the back of the hand was not that of the ordinary feigned eruption, but neither did it resemble any known dermatoses. The individual lesions were such as might be produced by local injury combined with

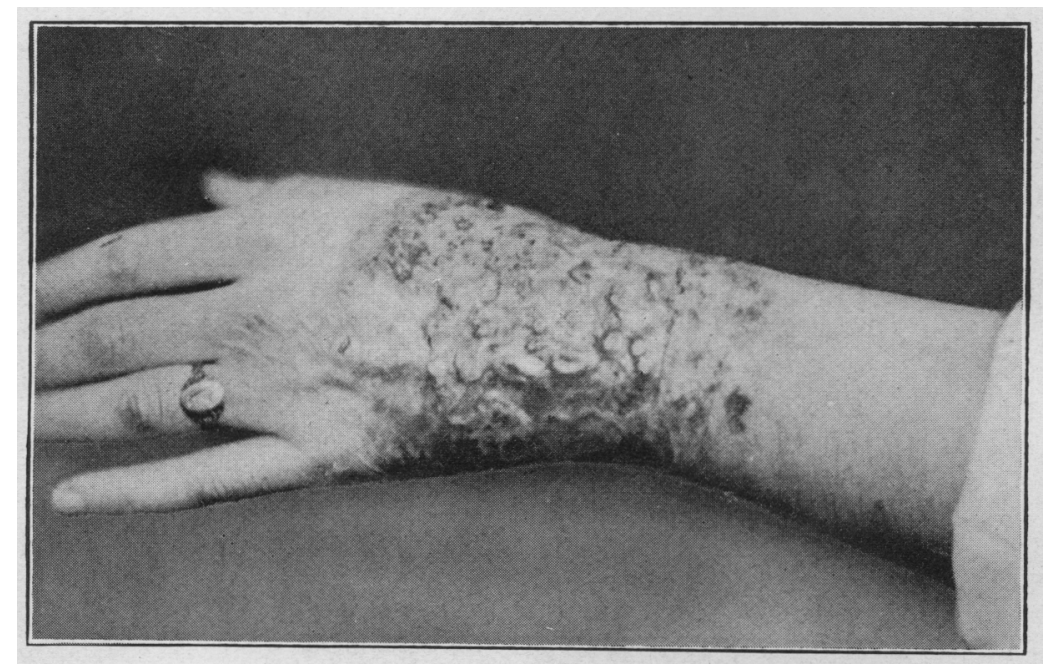

Neurotic excoriation on hand.

simple pus infection. It was not difficult, therefore, to arrive at the conclusion that the injury was probably self-produced. The patient, however, did not present the usual facies of the malingerer. There was not the impassive face, the dejected expression, the downcast eye of the malingering woman. She was alert, looked one in the eye and answered questions without evasion. When the opinion was given that the lesions were self-produced the doctor frankly said he could not believe it. The woman, however, readily admitted that this might be true, as she had found herself constantly picking at the hand, and could not avoid it. She was not secretive or on the defensive. If she was doing it, it was through a nervous impulse which she had not been able to resist, and she was ready to cooperate with us in meeting the situation.

Treatment and Course.-I advised the application of weak aluminum acetate solution compresses and an occlusive dressing that would prevent her from getting at the hand. Two and a half weeks later her physician employer wrote me that the hand had healed completely in about a week, but in order to prevent her from irritating the hand at night, she had had to put a muff on her other 
hand, and for a while it had been necessary for a nurse to watch her at night. It was at night, during her sleep, that she did most of the damage. Her physician, to whom I said nothing about neurotic excoriations of the skin, suggested in his letter that he thought she had not been producing this injury deliberately, but through nervousness, comparing the condition very aptly to biting of the fingernails. After a week and a half of treatment she needed dressings only during sleep, and was able to go on with her nursing as usual.

DISCUSSION

Dr. Schamberg thought Dr. Pusey did well to emphasize the distinction between the two types of factitious dermatitis which were very different in their nature and the motive which prompted them. The feigned eruptions that had as their motive a desire for morbid sympathy or escape from some unpleasant duty, were familiar as were also the so-called neurotic excoriations in which the underlying cause is an uncontrollable and vicious habit, often acquired more or less subconsciously in an effort to aid in the cure of the lesions. He had seen a number of cases of acne in which the patients had produced indelible scars on the face. The patients freely admitted their part in the production of the lesions of the face, but said the lesions would not heal until they were opened. The two types of factitious lesions were very different in their inception. Dr. Schamberg thought that one should also differentiate between neuropathic lesions of the skin of organic origin and those considered above. He recalled a patient who had been for many years under the care of Dr. Duhring whose hand was mutilated by a gangrenous process until it looked like a claw. Pathologic studies of the nerves in the amputated member were made by Professor Spiller of the University of Pennsylvania. Degenerative changes were found which were regarded as primary, but it was impossible to exclude secondary nerve change. He believed three conditions should be considered: the feigned eruptions, the neurotic excoriations and certain neuropathic changes which were due to nerve lesions.

DR. ORMSBY stated that some years ago he had recorded the cases of thirtyfour patients who had produced lesions on themselves, and he had seen a number of similar instances since that time. The question frequently arose as to whether these were self-inflicted or were of spontaneous origin. $\mathrm{He}$ believed the major portion were self-induced. He had seen none that were spontaneous, and he was therefore interested to hear Dr. Schamberg's report of a proved spontaneous gangrene-Dr. Corlett and a few others had described similar instances. The group of patients recorded by Drs. Pusey and MacKee, while having self-induced lesions, belonged to a different category, but that some of them may be similar was well illustrated in the case reported by Dr. Pusey. Had this patient been seen some years ago it probably would have been considered an example of feigned dermatitis. The history, together with the lesions in the light of our present knowledge, removed it from that group and properly placed it with neurotic excoriations.

Dr. ENGMan believed that the sexual element was important in these cases. Some years ago he and Dr. Schwab reported a case in which there was a decided sexual element. The young woman had, when picking her skin, a distinct sexual feeling: In the case of acne excoriation there was such a history, and it was an important fact in analyzing these cases to go into the sexual history. Sometimes, in the freudian sense, it was the basis of the trouble and these patients obtained some sexual gratification in picking the skin. 
Dr. HAzen said that he had seen a pruritus of the genitals develop when patients were unhappily married and also when they had failed to be married when they expected to, and he thought most cases of pruritus vulvae would fall into the same group. He believed that psychanalysis would be valuable in these cases, if it were possible to get a good man to cooperate.

DR. PUSEY (closing) said that he was familiar with the sexual element that complicated many cases of feigned eruption, but he was not inclined to think that this was an element that was apt to be encountered in neurotic excoriation. The impelling fact in these cases was the nervous impulse to pick at a lesion, and he was anti-freudian enough to believe that this impulse could reasonably be thought in most cases not to have a sexual element. He was particularly interested in the sharp mental distinction between the patient in the case he had just reported and the malingerers. He tried to bring out the contrast in the report. He had never seen a malingerer whose attitude had been the frank one of this patient. 